\title{
Circuit
}

Musiques contemporaines

\section{Le festival Musica et le Réseau Varèse The Musica Festival and the Réseau Varèse}

\section{Jean-Dominique Marco}

Volume 14, numéro 2, 2004

Montréal/Nouvelles Musiques

URI : https://id.erudit.org/iderudit/902314ar

DOI : https://doi.org/10.7202/902314ar

Aller au sommaire du numéro

Éditeur(s)

Les Presses de l'Université de Montréal

ISSN

1183-1693 (imprimé)

1488-9692 (numérique)

Découvrir la revue

Citer cet article

Marco, J.-D. (2004). Le festival Musica et le Réseau Varèse. Circuit, 14(2), 59-66. https://doi.org/10.7202/902314ar
Résumé de l'article

L'auteur s'interroge sur les outils de diffusion adoptés par la musique contemporaine en se basant sur les exemples du festival Musica de Strasbourg et du Réseau Varèse, dont il est le fondateur. En partant du principe que le processus de composition musicale contemporaine dans son aspect créatif et dans sa complexité, quels que soient le genre et l'esthétique musicale défendus, est une démarche artistique marginale dans une société où tout est fondé sur la rentabilité économique immédiate, où tout doit rapporter un profit et toucher le plus de consommateurs possible, il est essentiel que l'on préserve la différence. À cette fin, on se doit d'adopter une attitude combative pour permettre aux artistes de s'exprimer librement au sein d'organismes voués à la diffusion de leurs oeuvres. Il ne s'agit pas de créer des ghettos mais bien de mettre en place des structures favorables à la création musicale et susceptibles d'en rapprocher le public.
Ce document est protégé par la loi sur le droit d'auteur. L'utilisation des services d’Érudit (y compris la reproduction) est assujettie à sa politique d'utilisation que vous pouvez consulter en ligne.

https://apropos.erudit.org/fr/usagers/politique-dutilisation/ 


\title{
Le festival Musica et le Réseau Varèse
}

\author{
Jean-Dominique Marco
}

C'est avec beaucoup de modestie que je souhaite vous parler de communication ef de réseautage en évoquant le festival Musica et le Réseau Varèse, réseau européen pour la création et la diffusion musicales que j'ai fondé en 1999. Les questions que vous vous posez et les problèmes auxquels vous faites face sont un peu les mêmes qu'en Europe, et nous n'avons pas forcément trouvé les bonnes réponses ni adopté les bonnes solutions ${ }^{1}$. Nous sommes tous logés un peu à la même enseigne.

Ce qui est sûr, c'est que le processus de composition musicale contemporaine dans son aspect créatif et dans sa complexité, quels que soient le genre et l'esthétique musicale défendus, est une démarche artistique marginale dans une société où tout est fondé sur la rentabilité économique immédiate, où tout doit rapporter un profit et toucher le plus de consommateurs possible. Nous vivons dans un monde où tout devient normatif, où les comportements tendent à se standardiser pour mieux être manipulés. II s'agit de provoquer les mêmes envies chez le plus grand nombre d'individus afin de rentabiliser la production. La communication, par le biais de la publicité, est devenu l'art de la manipulation que l'on exerce sur les individus dès leur plus jeune âge. On nous donne l'impression d'une liberté de choix infinie alors que tout est fait pour nous influencer, nous conduire vers ce que d'autres ont choisi pour nous, à notre place. Bref tout est fait pour que nous soyons des consommateurs dociles et obéissants. Depuis longtemps, le marketing a aussi envahi le monde culturel. L'énorme influence qu'exerce l'audiovisuel, entre autres la télévision, sur le comportement et le goût de ceux qui les regardent ne fait qu'accentuer notre malaise face à une culture banalisée et identique pour tous. Où est le droit à la différence? Eh bien, chers amis, nous en sommes un peu les gardiens!

En effet, nous avons évidemment une autre conception de la société et de la culture. Nous nous battons pour que des artistes aient les moyens de s'exprimer de la manière la plus libre et la plus originale possible afin que l'art, la musique en particulier, puisse continuer à faire preuve d'originalité, de pertinence et, pourquoi pas, d'impertinence. Nous aimons la musique comme moyen d'expression, de réflexion, voire de contestation. La création n'est pas qu'un acte de complaisance, c'est aussi

1. Ce texte de conférence a été présenté en ouverture au colloque "Rencontre des musiques nouvelles au Canada organisé par le Conseil québécois de la musique du 9 au 11 mars 2003. La rencontre visait à discuter des problématiques reliées à la communication et au résautage dans le domaine des musiques nouvelles. Les discussion ont porté sur l'éventualité de la mise en place d'un véritable réseau pancanadien, de la création d'outils de réseautage et la conception d'un plan de diffusion des musiques nouvelles au Canada et sur ce que le Centre de musique canadienne pourrait entreprendre pour soutenir ces démarches communes. 
un acte de résistance. À côté de ce qui fonde notre culture patrimoniale, nous défendons ce qui innove, ce qui nous interpelle et ébranle nos certitudes en nous proposant de nouvelles explorations artistiques. Bien sûr, nous ne sommes pas là aujourd'hui pour faire le procès des musiques commerciales, véritables produits de consommation qui ont leur utilité. Elles répondent, en tout cas, à une demande importante et certaines sont d'ailleurs efficaces et d'assez belle facture. Beaucoup de ces artistes ne manquent pas de talent. Là n'est pas le problème.

Ce qui nous préoccupe, c'est de pouvoir permettre à nos artistes de travailler, même si ce qu'ils produisent n'est pas compris ni apprécié du plus grand nombre. Si l'on se réfère aux valeurs sacrées de la démocratie, la majorité exerce le pouvoir sans pour autant écraser ou mépriser la minorité qui a le droit de s'exprimer. Eh bien, nous sommes une minorité et nous réclamons ce droit en donnant la parole aux artistes, compositeurs et interprètes qui n'œuvrent pas forcément pour le grand public.

Alors, comment faire pour exister dans un tel univers? Je n'apporte évidemment aucune solution toute faite. Je ne puis que parler de mon expérience à la tête d'un festival, fondé il y a 20 ans, et d'un jeune réseau européen d'opérateurs culturels créé en 1999 et soutenu par l'Union européenne.

Je dirai qu'il nous faut d'abord les moyens de notre action. Nos recettes propres, directement issues de nos activités sont maigres et ne suffisent pas. Les mécènes et les commanditaires ne se bousculent pas aux portes des musiques nouvelles. Reste le soutien institutionnel, celui de l'État et des collectivités locales. II est fondamental. Sans ces aides et subventions, notre action est limitée, voire condamnée à l'impuissance. Les pays où la création développe ses réseaux sont ceux où les pouvoirs publics soutiennent ce type d'activités. Je pense par exemple à la France et à l'Allemagne, à la Finlande aussi.

Je crois ensuite que nous ressentons tous, opérateurs culturels et artistes, un certain isolement. Pour vaincre cet état, nous devons nous adapter aux nouvelles technologies, afin de communiquer davantage avec nos publics et nos partenaires privés et institutionnels. Nous devons nous adapter aussi aux méthodes et aux outils des organismes musicaux traditionnels qui contrôlent souvent les réseaux de diffusion, à commencer par les lieux de spectacle dont nous avons besoin. Notre univers est un petit milieu face aux moyens importants dont disposent les diffuseurs des musiques dites classiques ou de variétés. Pour exister, nous avons donc besoin des autres, de leurs moyens et de leurs outils. II nous faut sortir des ghettos où nous nous mettons parfois nous-mêmes, communiquer sans cesse sur ce que nous faisons et surtout nous réunir, nous unir à travers nos propres réseaux régionaux, nationaux et internationaux pour mieux diffuser nos musiques. 
[...] Nous devons tous nous sentir des coproducteurs et des coréalisateurs potentiels. La mise en commun de nos informations, de nos compétences et de certains de nos moyens est la seule possibilité de mieux servir les artistes créateurs et d'optimiser ainsi notre influence culturelle.

Musica est né en 1982 par la volonté du ministère de la Culture, plus précisément par celle de son Directeur de la Musique, Maurice Fleuret, qui souhaitait une nouvelle plateforme de rencontre entre les musiques d'aujourd'hui et le public le plus large possible. À la fin des années 1970, nous étions devant un constat d'échec inquiétant et menaçant pour la musique contemporaine : les œuvres d'aujourd'hui n'arrivaient pas à trouver un public suffisamment important pour continuer à être prises en compte de façon significative par les pouvoirs publics. Après l'essoufflement des festivals de Royan et de Metz, il fallait que cette musique puisse enfin trouver son public et le fidéliser. C'est l'une des missions qui fut confiée à Musica. II fallait que ce festival ait tout de suite du succès en drainant un public nombreux sous peine d'être abandonné après une première édition sans résultat probant.

Face à ce défi, une stratégie en quelques points fut mise en place:

1. Établir une programmation ouverte, visant à présenter au public les œuvres marquant les grandes étapes de l'évolution des esthétiques musicales du XXe à partir de la Seconde École de Vienne, Berg, Webern, Schœnberg et Stravinsky aussi. Par exemple, la première édition de Musica fut en grande partie consacrée à Edgar Varèse avec l'intégrale de ses œuvres, essentiellement écrites dans les années 1920. II fallait donner au public des repères lui permettant de se familiariser avec les différents courants esthétiques qui ont traversé la musique et alimenté toutes les querelles des années 1960 et 1970, tant à Paris qu'à Darmstadt ou encore à Donaueschingen, la Mecque de la musique contemporaine d'après-guerre. Les grands compositeurs furent présentés : Stockhausen, Boulez, Nono, Xenakis, Messiaen, Ives, Carter et bien d'autres encore. II s'agissait ensuite de confronter leurs musiques à la jeune création, à celle des compositeurs de moins de 35 ans. Ainsi, en 20 ans, avons-nous présenté près de 2000 œuvres, dont un tiers de créations et de premières françaises, de plus de 600 compositeurs, dont un tiers seulement étaient Français.

2. Ouvrir le festival aussi bien aux concerts qu'aux spectacles : opéra, spectacle musical, danse, spectacle multimédia... consacrant ainsi la pluridisciplinarité du projet artistique.

3. Bien marquer son territoire musical pour mieux pouvoir l'ouvrir à d'autres formes, dès qu'elles offrent une certaine originalité dans leur conception ou 
leur réalisation dans le domaine du jazz, des musiques improvisées, du rock, voire même de la chanson ou de tout autre genre iconoclaste.

4. Transformer une manifestation au contenu plutôt pointu pour un public restreint en un événement dans la ville, en s'appropriant le plus grand nombre de lieux de spectacles, si possible les plus insolites et les plus éclatés dans l'espace, pour que le festival puisse affirmer fortement sa présence et son identité. Bien des lieux à caractère industriel ou commercial se prêtaient fort bien à cet exercice. La médiatisation par une présence physique forte du festival dans la ville reste importante pour nous. La signalétique et l'image de chaque édition doivent devenir emblématiques et frapper par leur impact aussi bien l'habitant que l'étranger qui débarque dans la ville.

5. Réaliser le festival avec une grande exigence artistique et technique, mais aussi dans un esprit festif et une grande convivialité avec le public. Un public composé aussi bien de connaisseurs de ces musiques (professionnels, artistes, élèves des conservatoires, mélomanes convaincus...) que d'auditeurs néophytes mais animés par la curiosité et l'envie de découvrir les créateurs de leur temps. Il était impératif que chacun se sente à sa place dans la manifestation, sans complexe ni appréhension. L'esprit festif et la convivialité de l'accueil contribuèrent au bien-être de l'auditeur. Aujourd'hui, je peux affirmer que les spectateurs de Musica, notamment les fidèles, se sont vraiment approprié la manifestation. Nous organisons de temps en temps des soirées dansantes, tard le soir après les concerts, pour permettre au public de se retrouver avec nous et les artistes dans une ambiance décontractée et joyeuse.

6. Médiatiser autant que possible le festival à travers des collaborations avec les grands médias nationaux et régionaux. Dès la première année, quelques suppléments dans des quotidiens et hebdomadaires importants et intéressés par notre démarche, installèrent rapidement la notoriété de Musica au point d'attirer, en plus de notre public cible, tout un public à priori peu motivé, sinon snob, uniquement séduit par la médiatisation de l'événement se déroulant dans sa ville. Certains se sont enfuis, épouvantés par la musique que nous proposions. Beaucoup d'autres sont restés et sont devenus, avec le temps, d'ardents défenseurs des musiques d'aujourd'hui.

7. Tisser de véritables réseaux de partenariats avec les élus locaux et nationaux, sans oublier les responsables européens, nombreux à Strasbourg, les responsables économiques et sociaux de la région. Is sont des relais d'opinion importants et doivent être convaincus de la nécessité et de l'importance d'une telle manifestation pour l'image de modernité de leur ville ou de leur région. Ce sont les premiers à défendre avec efficacité la notoriété de la manifestation. Ce n'est plus tant le contenu artistique qui importe ici que la capacité du festival à renforcer la réputation culturelle d'une ville dont les enjeux européens sont considérables. 
8. Enfin, collaborer avec les autres institutions culturelles de la ville, de la région et de toute la zone franco-germano-suisse du bassin rhénan. Nous travaillons avec les orchestres, les ensembles, les opéras, les centres culturels et les théâtres, sans oublier les écoles de musique, notamment le Conservatoire de Strasbourg avec lequel nous avons développé une politique de résidence de compositeurs. II s'agit d'un véritable réseau de collaborations multiples qui nous permet de renforcer nos moyens et notre capacité d'action en les multipliant.

Aujourd'hui, Musica a 20 ans et s'est durablement installé dans le paysage culturel de Strasbourg. La manifestation est respectée même par ceux qui n'aiment pas les musiques qu'elle défend. Elle est considérée par tous comme étant un atout pour l'image de cette ville. Avec ses quelque 20000 spectateurs par édition, le festival s'est imposé en France comme l'un des événements majeurs dans le domaine de la diffusion et de la création de la musique contemporaine. Vous aurez compris que l'un des soucis majeurs de notre action aura consisté à démocratiser autant que faire se peut notre musique en pratiquant son insertion sociale, voire même sa reconnaissance sociale dans le tissu socioéconomique, politique et culturel dans lequel nous la faisions évolver.

Mais au fil des ans, les difficultés budgétaires que connaît l'Europe en pleine mutation ont poussé peu à peu les États et les collectivités publiques à réduire leurs aides. Même si mon festival n'a pas été touché jusqu'à présent, les opérateurs culturels européens, dont je suis, sentent bien de plus en plus la nécessité de s'unir et de collaborer pour une meilleure gestion des productions et de leur circulation dans cet espace européen. Évidemment, nécessité et désir ne font pas forcément ni toujours bon ménage. Les programmateurs sont souvent des individualistes qui ont peur de perdre leur originalité et la paternité des projets qu'ils mettent sur pied. Ils ont tendance à fonctionner par réseaux d'affinité et de complicité, sorte de clubs informels d'échange d'information et de tuyaux. C'est un tel club que quelques partenaires, dont Musica, tentèrent de mettre en place en 1990. En vain, l'expérience échoua et aucun projet ne put se concrétiser.

Un événement important changea la situation en 1998, lorsque l'Union européenne décida de mettre en place une nouvelle politique en matière d'aide culturelle directe, sous forme de subventions de la Commission européenne dans le cadre d'un programme intitulé Culture 2000. Partant du constat que la culture était l'un des secteurs privilégiés de la mobilité et des échanges à l'échelle des individus et des savoir-faire, et qu'elle anticipait et favorisait la complexe élaboration de l'Europe en produisant du symbolique, de l'imaginaire, du poétique, du sens qui transcendent les actes économiques et monétaires, l'Union européenne a décidé que les arts et le patrimoine devaient être une priorité dans le dispositif communautaire.

Le programme Culture 2000 couvre la période 2000-2004. Son but est notamment de promouvoir la création, la diffusion transnationale de la culture et la mobilité des artistes, des créateurs, des autres acteurs et professionnels de la culture ainsi 
que la diffusion de leurs œuvres, en mettant l'accent sur les jeunes et sur la diversité culturelle. Pour mettre en place cette politique, la Commission européenne a créé des Points de contact Culture dans la plupart des pays européens. Ces structures apportent une assistance technique aux candidats qui souhaitent obtenir l'aide de I'UE. Elles informent l'ensemble des professionnels du secteur culturel, les administrations nationales et régionales sur ce nouveau dispositif. Elles apportent enfin leur expertise aux professionnels pour la mise en réseau d'initiatives européennes, la recherche de partenaires et toute démarche susceptible de favoriser le développement de projets de coopération et de mobilité en Europe ${ }^{2}$. L'enveloppe financière pour l'exécution du programme Culture 2000 pour la période 2000-2004 est de 167 millions d'euros.

C'est dans cet esprit et avec le soutien du Département des affaires internationales du ministère de la Culture et de la Communication que j'ai pris l'initiative, fin 1998, de rassembler des partenaires, opérateurs culturels comme moi, et de fonder un réseau européen de coopération artistique. Le projet prendra sa forme définitive en novembre 1999 par la création d'une association intitulée Réseau Varèse, réseau européen pour la création et la diffusion musicale, qui regroupe aujourd'hui 16 membres de 11 pays : Allemagne (3), Autriche (1), Belgique (1), Finlande (1), France (3), GrandeBretagne (2), Grèce (1), Hongrie (1), Italie (1), Norvège (1) et Portugal (1) $)^{3}$.

Pour fonctionner dans de bonnes conditions, nous avons établi un règlement qui nous permet à la fois d'être clairs entre nous et surtout de satisfaire aux exigences de l'UE pour bénéficier de son soutien car, sans ce dernier, le Réseau ne pourrait agir, faute de moyens. En voici les principaux éléments. Le Réseau est un lieu d'information ouvert et efficace pour toutes les productions ayant un véritable développement européen, lancées ou souhaitées par un ou plusieurs membres de l'association. Les propositions doivent être faites le plus tôt possible, même si elles ne sont qu'à l'état de projet ou si le dossier ne réunit pas dès le départ tous les critères d'inscription au programme du Réseau. La circulation de cette information est essentielle pour un bon fonctionnement du Réseau.

Pour qu'un projet puisse être sélectionné, puis labellisé par le Réseau Varèse et bénéficier le cas échéant d'une aide par le biais de financements européens recueillis par le Réseau (accords de coopération triennaux), les critères suivants doivent être respectés :

1. Le projet doit clairement s'articuler autour d'un compositeur contemporain, d'une œuvre musicale ou d'un programme réunissant plusieurs œuvres musicales d'aujourd'hui.

2. Les interprètes et les équipes artistiques doivent être connus ou reconnus par plusieurs membres du Réseau.

3. Le projet doit motiver ou réunir au moins trois membres du Réseau, de deux pays au minimum.
2. Adresse du site Relais Culture Europe : http://wnw.relais-culture-europe.org.

3. Allemagne : Schauspielfrankfurt, Konzerthaus, Hebbel Theather, Maerzmusik/ Berliner Festispiele;

Autriche: Wien Modern; Belgique : Festival Ars Musica, Ircam, T\&M; Grande Bretagne : Huddersfield Comtemporary Music Festival, South Bank Centre; Grèce : Athens Concert Hall ; Hongrie : Budapest Autumn Festival ; Italie : Fondazione Romaeuropa; Norvège : Festival Ultima; Portugal : Casa da musica. 
4. Le projet doit être à l'étape de l'élaboration ou encore à celle de la réalisation, et le producteur délégué s'engage de manière sérieuse afin de garantir la création et la diffusion auprès des différents membres du Réseau, selon un calendrier qui respecte les impératifs des membres du Réseau.

5. Les projets pourront se situer indifféremment dans les domaines

- du spectacle musical ou lyrique;

- de la musique d'orchestre avec ou sans chœur ;

- de la musique de chambre ou chorale;

- de la pédagogie.

Pour la création et/ou la reprise d'œuvres ou de productions existantes, l'aide financière du Réseau portera prioritairement sur :

- la diffusion des productions, l'aide sera alors attribuée aux membres du Réseau diffusant les productions;

- la production, une aide directe sera octroyée, si le producteur délégué est membre du Réseau;

- la commande au compositeur, si l'œuvre est programmée et diffusée par plusieurs membres du Réseau.

Le Réseau veillera à une juste répartition géographique des projets inscrits à son programme.

Sur proposition du bureau, les projets inscrits au programme du Réseau seront adoptés par l'Assemblée générale.

Sur proposition du bureau, les montants des aides attribuées à chaque projet seront adoptés par l'Assemblée générale suivant l'obtention des fonds européens.

\section{Présentation des projets}

Afin de permettre une lecture homogène et rapide des projets, il est souhaitable de présenter les projets sous forme de fiche réunissant les informations suivantes:

1. nom du compositeur/œuvre ou programme;

2. équipe artistique principale (distribution);

3. date de création, calendrier de diffusion de la production; 
4. enjeu financier (estimation, ordre de grandeur) :

- budget prévisionnel de production

- budget prévisionnel de diffusion;

5. producteur;

6. partenaires d'ores et déjà (coproducteurs, diffuseurs) :

- engagés : Réseau Varèse/hors Réseau

- intéressés : Réseau Varèse/hors Réseau.

La fiche sera bien sûr complétée par tout document - audio, audiovisuel, partition ou argumentation - susceptible d'apporter des éclaircissements sur le projet.

Ce système mis en place et respecté a parfaitement fonctionné jusqu'à présent. Nous avons bénéficié d'un soutien triennal 2000/2002 de l'UE d'un montant de 300.000 euros qui nous a permis de réaliser et de soutenir 12 grandes opérations pour plus de 60 représentations dans l'ensemble des pays du Réseau. Le budget total de ces opérations représente un peu plus de 3 millions d'euros. Nous avons introduit un nouveau dossier d'aide à l'UE pour la période 2003/2005 pour pouvoir continuer et amplifier cette mission. 